\title{
My nutrition index: a method for measuring optimal daily nutrient intake
}

\author{
Stefanie A. Busgang ${ }^{1 *+}$, Ashley J. Malin ${ }^{2+}$ and Chris Gennings ${ }^{1}$
}

\begin{abstract}
Background: Adequate nutrition is essential for individual and population level health. However, determining adequacy of daily nutrient intake in research studies is often challenging given the unique nutritional needs of individuals. Herein, we examine construct, predictive, criterion, content, and concurrent validity of a dietary analytic tool - My Nutrition Index (MNI) for measuring nutrient intake in relation to personalized daily nutrient intake guidelines. MNI gauges adequacy of an individual's daily nutrient intake based on his or her unique demographic and lifestyle characteristics. MNI accounts for potential adverse effects of inadequate and excess nutrient consumption.

Methods: MNI, calculated based on 34 nutrients, provides an overall index score ranging from 0 to 100, with higher scores reflecting a more nutritious diet. We calculated MNI scores for 7154 participants ages 18-65 in the National Health and Nutrition Examination Surveys (2007-2014) by using average nutrient intakes from two 24-h dietary recalls. Survey-weighted binary logistic regression models were used to assess associations between MNI scores and obesity, depression, health perceptions, and past or present cardiovascular disease.

Results: Higher MNI scores were associated with lower prevalence of self-reported cardiovascular disease $(\mathrm{OR}=0.69$, $\mathrm{Cl}: 0.52,0.92, p=0.012)$, depression ( $\mathrm{OR}=0.76, \mathrm{Cl}: 0.65,0.90, p<0.001)$, and obesity $(\mathrm{OR}=0.92, \mathrm{Cl}: 0.87,0.99, p=0.016)$, as well as more favorable health perceptions ( $\mathrm{OR}=1.24, \mathrm{Cl}: 1.13,1.37, p<0.001)$.
\end{abstract}

Conclusions: MNI provides an individualized approach for measuring adequacy/sufficiency of daily nutrient intake that can validly be employed to assess relationships between nutrition and health outcomes in research studies.

Keywords: Micronutrients, Nutritional epidemiology

\section{Background}

Adequate nutrition is essential for individual and population-level health [1-4], and better understanding the role of dietary nutrient quality in health outcomes can facilitate health improvements. However, capturing the nutritional value of a comprehensive diet in population-based studies is often challenging because nutritional guidelines vary among individuals based on their demographics,

\footnotetext{
*Correspondence: Stefanie.busgang@mssm.edu

†tefanie A. Busgang and Ashley J. Malin contributed equally to this work.

${ }^{1}$ Department of Environmental Medicine and Public Health, Icahn School of Medicine at Mount Sinai, New York, USA

Full list of author information is available at the end of the article
}

unique physiology, health status and physical activity level [5].

There are several different methods commonly implemented for measuring quality and/or adequacy of daily nutrient intake in research studies. These include: calculating indices such as the Healthy Eating Index (HEI) [6-9], measuring adherence to diets or nutritional recommendations empirically related to more favorable health outcomes, such as the Mediterranean Diet (MeDi), Dietary Approach to Stop Hypertension (DASH) or American Heart Association diet and lifestyle recommendations [10-12], or applying outcome-independent statistical approaches (i.e. factor analysis or cluster analysis) to characterize quality of daily nutrient intake from food frequency questionnaire or dietary recall data [13]. 
While each method provides valuable information on nutritional intake, these methods do not account for individual characteristics that influence daily nutrient intake guidelines, such as age, smoking status, disease states and/or physical activity level for example.

My Nutrition Index (MNI) provides an individualized and comprehensive approach to measuring adequacy and optimality of daily nutrient intake. The metric was shown to have predictive validity by demonstrating wellestablished associations between nutrition during pregnancy on birthweight and cognitive function in children [14]. MNI measurements are based on an individual's unique nutritional needs (i.e., content validity), according to the Dietary Reference Intakes, developed by the National Academies of Sciences, Engineering and Medicine [15]. MNI accounts for potential adverse effects of inadequate and excess consumption of certain macroand micro-nutrients by assigning the highest score per nutrient when the nutrient intake is within the recommended level and assigning lower scores the further from the recommended level [16-19]. Herein, we describe the characteristics of MNI and explore the distribution of MNI scores in the US adult population. First, we further examined the predictive validity of the metric by examining well-established associations between nutrition, using MNI scores, and population-level health outcomes including obesity, depression, health perceptions, and past or present cardiovascular disease among adults in the US. We expected that MNI scores would validly quantify nutritional adequacy and thus be associated with more favorable health outcomes in all measured domains. Second, we examined concurrent validity by comparing distributions of MNI scores between men and women, and between smokers and nonsmokers. Third, we examine content and construct validity by assessing the correlation between the MNI index and energyadjusted individual nutrients. Fourth, we examined criterion validity by comparing the associations between MNI and our selected health outcomes to the associations of HEI and the same health outcomes to determine if our measure is similar to the current gold standard for population studies. Lastly, we examined convergent and construct validity by examining the correlation between MNI and HEI.

\section{Methods}

\section{Participants}

Participants included 18-64year-olds participating in The National Health and Nutrition Examination Survey (NHANES) cycles 2007-2014 [20]. Adults who had two complete, valid, 24-h dietary recall, as well as complete covariate data were eligible for inclusion in analysis. Additionally, we only included participants who indicated that their 24-h dietary recall was consistent with their typical eating patterns and we excluded participants who indicated that they were on a special diet (because we could not determine their length of time on that diet). Additionally, we limited analyses to participants whose dietary recall energy values were within 3 times of their target calories based on their body size, sex, physical activity, and age (i.e., $0.33<$ energy/target calories $<3.0$ ). Ramirez-Silvia et al. [21] suggest limiting analyses to energy values within $50 \%$ of target calories, however we expanded this range to account for potential extreme increases and/or decreases in caloric intake that may correspond with the presence of depressive episodes, obesity and/or cardiovascular disease [22, 23]. There were 7154 participants who met inclusion criteria. After applying survey weights provided by NHANES, the overall sample of 7154 represented approximately 133 million adults in the United States. For analyses including depression and cardiovascular disease outcomes, we further excluded participants who were taking medication to treat that particular health condition. Specifically, we excluded participants who reported taking psychotropic medication, (i.e. anti-depressants, anti-convulsants, and antipsychotics) because people taking these medications may appear less depressed according to the depression screener, thus mis-representing their health condition The resulting sample size for testing the association between MNI scores and depression was 6105 (weighted $\mathrm{N}=\sim 73.7$ million). Similarly, when examining associations between MNI scores and cardiovascular disease, we excluded participants who were taking cardiovascular medication (e.g. antiarrhythmic agents, diuretics, vasopressors, etc.), resulting in a sample size of 5860 (weighted $N=\sim 72.6$ million). We did so because participants taking these medications may be doing so for preventative reasons which may impact their cardiovascular health independently of nutritional intake. Lastly, selfreported pregnant women were excluded from the associations assessing obesity, since the increased weight gain from pregnancy would result in misclassification of these women as obese. A flow chart indicating inclusion and exclusion criteria is shown in Fig. S1.

\section{My nutrition index}

My Nutrition Index (MNI) is a novel index that measures nutritional value of a specified daily diet based on the foods consumed in terms of how closely it adheres to the Institute of Medicine's nutritional guidelines. It provides an overall index score ranging from 0 to 100 , with higher scores reflecting a more nutritious diet. MNI is calculated based on quantification of 34 macro- and micronutrients that are recommended to satisfy an individual's daily nutritional needs and accounts for caloric intake 
and alcohol, sugar, and caffeine consumption [15-19]. It assigns higher scores for micro- and macro-nutrient concentrations that fall within the recommended intake ranges provided by the Dietary Reference Intakes, developed by the National Academies of Sciences, Engineering and Medicine [16-19, 24-27]. Often, these guidelines are based on recommended dietary allowances (RDAs) but in the absence of an RDA they report the Acceptable Macronutrient Distribution Range, adequate intake, or tolerable upper limit where appropriate. Caffeine recommendations are based on the Food and Drug Administration upper limit of $400 \mathrm{mg} /$ day for health adults [28]. It assigns lower scores if intake for a given nutrient deviates from this optimal range (i.e. deficient or excess intake). For example, a pre-adolescent between the ages of 9-14 would have a perfect score for zinc if his or her daily intake was $8 \mathrm{mg}$. The upper limit of zinc for this age group is $23 \mathrm{mg} / \mathrm{d}$ so any concentration greater than 23 would result in a lower score for zinc. Something less than 8 would also result in a lower score. For a nutrient such as potassium, the recommended level for adults is $4700 \mathrm{mg} / \mathrm{d}$ with no upper limit. Any level above 4700 would result in a perfect score and lower levels result in a lower score. The final score is calculated as the geometric mean across nutrients. Thus, a perfect MNI score would be obtained if adequate intake of all nutrients is met through diet.

MNI also incorporates dietary restrictions, individual characteristics (i.e. age, height, weight, sex, etc), activity level, and health behaviors into its calculations. Specifically, MNI can accommodate dietary recommendations based on smoking status, presence of hypertension, pregnancy, lactation, and need for a low fat, low sugar, or high protein diet, as well as any other condition for which there are special recommendations. For the current analysis, age, height, weight, sex, activity level, hypertension, pregnancy, and smoking were accounted for, while other characteristics were not because they were not available in the current dataset. In other contexts when these variables are available, the optimal ranges for specific nutrients can be adjusted if the participant has a dietary restriction or condition. Participants on special diets were excluded, as mentioned previously, since there is no information about what the special diet is or how long they have been on it. Activity level was estimated using self-reported questions related to recreational and work activity. A 5-point scale was created, with 5 being the highest activity level, based on the following responses: 5 If an individual responded to "yes" to both vigorous recreational activity and work activity (paq650 and paq605), 4 if an individual responded "yes" to only one vigorous type of activity, 3 if an individual did not respond to "yes" to either vigorous activities but did respond "yes" to both moderate recreational and work activity (paq655 and paq620), 2 if an individual did not respond "yes" to either vigorous activities but did respond "yes" to only one of the moderate types of activities, and 1 was assigned otherwise. Hypertension status, pregnancy, and smoking status were determined by self report (bpq020, RIDEXPRG, and smq020 respectfully). Therefore, MNI is calculated per participant based on published or clinical guidelines for recommended target nutrient intake ranges specific to their characteristics [15].

The following nutrients are included in MNI:

- macronutrients: protein, carbohydrates, total fat, saturated fat, monounsaturated fat, polyunsaturated fat, energy, fiber, cholesterol;

- vitamins: A, thiamin (B1), riboflavin (B2), niacin, pantothenic acid (B5), B6, folate (B9), B12, C, D, E and $\mathrm{K}$;

- minerals: calcium, chloride, iron, magnesium, manganese, phosphorus, sodium, potassium, selenium, zinc; and

- other: alcohol, sugar and caffeine.

In addition to considering the degree to which nutrients fall within an individual's recommended range, the MNI score incorporates the degree of agreement between target (i.e. recommended) caloric intake and observed diet-based calories. To determine total daily energy needs per individual, MNI utilizes the Mifflin-St Jeor equations for basal metabolic rate (BMR) which are functions of sex, weight, height and age multiplied by a 5-level physical activity factor. The lowest level is multiplied by 1.20 , the second level by 1.375 , the third level by 1.55 , the fourth level by 1.725 , and the highest level by 1.90 [29].

\section{Dietary nutrient intake}

Dietary nutrient intake was assessed via two 24-h dietary recalls within a 3-10-day period. Dietary recalls were administered during an in-person and telephone interview respectively using the Automated Multiple Pass Method data collection tool developed by the United States Department of Agriculture [30] . Participants were asked to report the foods and beverages that they consumed over the past 24-h and to indicate whether these foods were characteristic of their regular eating patterns (i.e. "Was the amount of food that you ate yesterday much more than usual, usual, or much less than usual?'). Nutrient levels from food items are obtained via the Food and Nutrient Database for Dietary Studies (FNDDS) [31] The National Center for Health Statistics also determined whether 24-h dietary recalls were reliable. The average nutrient intake from both reliable and typical recalls were 
included in analyses. HEI scores were calculated using a SAS macro for the 2015 version of HEI provided by the National Cancer Institute (https://epi.grants.cancer.gov/ hei/sas-code.html).

\section{Health outcomes}

Though dietary patterns have been linked to many physical and mental health outcomes, for the purpose of this paper we selected four health outcomes shown to be related to nutrition in prior research: health perceptions, depression, obesity, and cardiovascular disease [32-39]. The question regarding self-perceived health asked: "Would you say (your/Study Participant's) health in general is. . excellent, very good, good, fair or poor?". There were two variables reflecting self-perceived health: one that was measured via a home interview and one that was measured during the mobile examination center (MEC) visit. We utilized the variable measured from the home interview, because it had no missing data while the variable measured during the MEC visit had missing data for 762 participants.

Depressive symptoms were measured via the Patient Health Questionnaire (PHQ-9) during the MEC visit using a computer-assisted personal interview system. The PHQ-9 incorporates DSM-IV depression diagnostic criteria and has been validated for use in clinical and research settings [40-42]. It is a 9-item self-report measure designed to determine the frequency of depressive symptoms over the past 2 weeks. Each item receives a score between 0 and 3 and the maximum score attainable is 27. A score above 10 reflects the presence of selfreported depressed mood.

Obesity was defined according to the World Health Organization criteria of Body Mass Index (BMI) $=>30 \mathrm{~kg} / \mathrm{m}^{2}$ [43]. Height and weight were measured during the MEC visit and BMI was calculated as weight in kilograms divided by height in meters squared, rounded to one decimal place. Though several studies have shown that BMI may not be an optimal measure of adiposity, Nutall et al. (2015) reviewed several studies which showed that being a little slightly overweight, according to BMI ranges, results in lower morbidity and mortality. Nutall also points to several studies where BMIs greater than 30 were an indication of higher mortality [44].

Lastly, to assess the presence of current or past cardiovascular disease, participants over the age of 20 years old were asked 5 separate questions regarding whether they had ever been diagnosed with the following conditions: congestive heart failure, coronary heart disease, angina pectoris, heart attack, or stroke. Participants who indicated that they had or have any of these conditions were considered to have past and/or current cardiovascular disease respectively [45].

\section{Covariates}

Covariates were selected a priori based on being empirically related to nutrient intake/metabolism and health outcomes of interest in prior studies [46-53]. They included: age, sex, race/ethnicity, education level and healthcare use. Education level was defined by a 5-level categorical variable ranging from less than 9th grade to college graduate or above. We adjusted for healthcare use as this may be a proxy for other health behaviors that may influence health outcomes and it may also be associated with dietary nutrient intake.

\section{Statistical analysis}

We applied dietary sampling weights, specifically the two-day weight, using survey procedures in SAS 9.4 to account for survey non-response, the clustered sample design, over-sampling, post-stratification, sampling error, differential allocation by day of the week for the dietary intake data collection, and to permit generalization to non-institutionalized adults in the United States population [54].

We calculated binary variables for each health outcome to examine its relationship with MNI scores dichotomously. For health perceptions, we computed a variable of favorable perceived health $=1$ and unfavorable perceived health $=0$, to compare those who rated their health as excellent, very good, and good (1) to those who rated their health as fair or poor (0) [55]. For remaining outcomes, we computed a binary variable of depressed $\operatorname{mood}($ i.e., $\mathrm{PQH}-9$ score $=>10)=1$ and non-depressed $\operatorname{mood}($ i.e., $\mathrm{PQH}-9$ score $<10)=0$; obese $(\mathrm{BMI}=>30)=1$ and non-obese $(\mathrm{BMI}<30)=0$; and current or past cardiovascular disease: yes $=1$, no $=0$. Four survey-weighted multivariable logistic regression models examined associations between MNI scores and each binary health outcome after adjustment for covariates. We converted MNI scores to a 10-point scale for regression analyses to better capture meaningful changes in dietary quality. Whereas nutrient intake may change slightly from day to day (i.e. captured by a few points change in MNI score on a 100-point scale), a 10-point change is more likely to reflect meaningful differences in nutritional intake. Spearman correlations were used to assess the correlation between MNI and individual nutrients, adjusted for energy. We also conducted analyses comparing distributions of MNI scores to HEI scores, as HEI is a valid and reliable nutrient measurement index that is widely used in research studies [56]. Different from MNI, HEI is based on food consumption patterns recommended by the US Dietary Guidelines (2015-2020). Spearman correlations were used to assess the correlation between MNI and HEI. Lastly, we examined associations between MNI and HEI scores, and compared their associations with the 
health outcomes examined herein. HEI scores range from 0 to 100 but, as with MNI scores, were converted to a 10-point scale for ease of interpretation. Additionally, for comparisons of associations of MNI and HEI with health outcomes, we centered and scaled MNI and HEI scores to account for differences in their distributions.

\section{Results}

Descriptive statistics for socio-demographic characteristics and health outcomes are presented in Table 1. The prevalence of each health outcome remained consistent across all NHANES cycles examined. MNI scores were approximately normally distributed, with the majority of participants having MNI scores between 50 and 70 and few participants having very low (i.e. $<20$ ) or very high (i.e. > 80) scores (Fig. 1). Distributions of MNI scores stratified by sex and smoking status are depicted in Fig. 2. Mean MNI scores were, on average, approximately 10 points higher for women than for men and for nonsmokers than smokers. Spearman correlations between MNI scores and individual nutrients, adjusted for caloric intake resulted in positive correlations for all vitamins and most nutrients that promote health (i.e. "good nutrients") and negative correlations for most nutrients that tend to detract from health when consumed in excess (Fig. 3).

Associations between MNI scores and health outcomes, after adjustment for covariates, are presented in Table 2. Higher MNI scores were associated with significantly lower odds of experiencing past or present CVD $(\mathrm{OR}=0.69,95 \% \mathrm{CI}: 0.52-0.92, p=0.012)$, reporting symptoms of depression $(\mathrm{OR}=0.76,95 \% \mathrm{CI}$ : $0.65-0.90$, $p<0.001)$, or being obese (OR $=0.92,95 \%$ CI: $0.87-0.99$, $p=0.016)$. Higher MNI scores were associated with significantly higher odds of reporting more favorable health perceptions $(\mathrm{OR}=1.24,95 \% \mathrm{CI}$ : 1.13-1.37, $p<0.001)$.

Similar to the distribution of MNI scores, the distribution of HEI scores was approximately normal; however, it had smaller variance (Fig. 4). MNI and HEI scores were moderately positively correlated $(r=0.39, p<0.001$; Fig. 5); however, a curvilinear association was evident graphically such that the association is closer to identity for higher scores (i.e. above 50). Survey-weighted logistic regression of associations between HEI scores and health outcomes, after covariate adjustment, yielded similar associations to those found between MNI scores and health outcomes (Table 3). However, the magnitude of association between HEI scores and obesity was larger than between MNI scores and obesity.

\section{Discussion}

It is well established that adequate dietary nutrition is essential for health [57]. However, relationships between dietary nutrient intake and specific health outcomes are often complex and difficult to measure [5, 58]. My Nutrition Index (MNI) quantifies dietary nutritional value based on an individual's characteristics, according to established dietary guidelines. It provides an overall index score that is adjusted for body size, age, sex, physical activity level, health status, and certain behaviors (see example in Appendix).

We examined MNI scores among adults participating in NHANES from 2007 to 2014 who reported two 24-h dietary recalls that were typical of their daily diet. We found that MNI scores were normally distributed with a mean of 50.8 and a median of 52.8. This suggests that most US adults tend to eat moderately nutritious diets. Consistently, findings from a study on dietary patterns among adults participating in NHANES from 2011 to 2012 found that just over $50 \%$ followed intermediately healthy diets [59]. Interestingly, we also found that MNI scores were higher among women and non-smokers, compared to men and smokers respectively. These findings are also consistent with prior studies showing that women and non-smokers tend to report adherence to more healthful dietary practices [60, 61]. For example, women have been shown to be more compliant with the Mediterranean diet [39], and non-smokers tend to consume more fruits and vegetables [62-64].

We also found that higher MNI scores detected anticipated and important associations between healthy eating and more favorable health outcomes. Specifically, a 10 -point increase in MNI score was associated with 0.83 (17\%) lower odds of having past or present CVD, 0.87 (13\%) lower odds of reporting feeling depressed, 0.97 (3\%) lower odds of being obese, and 1.08 (8\%) higher odds of reporting excellent or very good health. These findings are consistent with prior studies showing that obese adults are more likely to suffer from micronutrient inadequacies, and that consuming a more nutritious diet may decrease the risk of depression, CVD and death from CVD [36, 65-70]. Thus, MNI captures associations between dietary nutritional adequacy and health outcomes in population-based studies in the expected directions.

We also compared distributions of MNI and HEI scores, as well as their relationships with health outcomes, as the HEI is a widely used, valid and reliable measure of nutritional intake in population-based studies. HEI was developed by the USDA to measure alignment between specific food group choices and USDA dietary guidelines [56]. Thus, unlike MNI, it does not quantify micronutrients, adjust for individual characteristics, or account for potential adverse effects from excess micronutrient intake. Similar to MNI scores, we found that HEI scores among NHANES participants were normally distributed; however, MNI scores were more 
Table 1 Sociodemographic characteristics of the study sample from NHANES cycles 2007-2014

\begin{tabular}{|c|c|c|c|}
\hline & $\begin{array}{l}\text { Unweighted } \\
\text { Frequency } \\
\text { ( } n=7154)\end{array}$ & $\begin{array}{l}\text { Unweighted } \\
\%\end{array}$ & $\begin{array}{l}\text { Weighted \% } \\
(N=87,869,105)\end{array}$ \\
\hline \multicolumn{4}{|l|}{ Sex } \\
\hline Male & 3622 & 50.6 & 50.9 \\
\hline Female & 3532 & 49.4 & 49.1 \\
\hline \multicolumn{4}{|l|}{ Education } \\
\hline Less than 9th grade & 564 & 7.9 & 4.0 \\
\hline 9-11th grade & 957 & 13.4 & 9.9 \\
\hline High school grad/GED or equivalent & 1579 & 22.1 & 21.4 \\
\hline Some college or Associates of Arts & 2101 & 29.4 & 31.3 \\
\hline College graduate or above & 1953 & 27.3 & 33.4 \\
\hline \multicolumn{4}{|l|}{ Race } \\
\hline Mexican American & 1154 & 16.1 & 8.7 \\
\hline Other Hispanic & 684 & 9.6 & 4.9 \\
\hline Non-Hispanic White & 3327 & 46.5 & 71.0 \\
\hline Non-Hispanic Black & 1233 & 17.2 & 8.8 \\
\hline Other race/Multi-racial & 756 & 10.6 & 6.7 \\
\hline \multicolumn{4}{|l|}{ Pregnant (females only) } \\
\hline No & 3443 & 97.5 & 97.4 \\
\hline Yes & 89 & 2.5 & 2.6 \\
\hline \multicolumn{4}{|l|}{ Smoker } \\
\hline No & 5539 & 77.4 & 79.1 \\
\hline Yes & 1614 & 22.6 & 20.9 \\
\hline Missing & 1 & & \\
\hline \multicolumn{4}{|l|}{ Routine use of healthcare } \\
\hline No & 1402 & 19.6 & 17.5 \\
\hline Yes & 5752 & 80.4 & 82.5 \\
\hline \multicolumn{4}{|l|}{ Self-reported Health Status } \\
\hline Good, Fair, Poor & 1283 & 17.9 & 13.3 \\
\hline Excellent, Very good & 5866 & 82.1 & 86.7 \\
\hline Missing & 5 & & \\
\hline \multicolumn{4}{|l|}{ Self-reported Depression } \\
\hline No & 6188 & 92.8 & 93.4 \\
\hline Yes & 481 & 7.2 & 6.6 \\
\hline Missing & 485 & & \\
\hline \multicolumn{4}{|l|}{ Obesity (elevated BMI) } \\
\hline$<30$ & 4636 & 65.6 & 67.2 \\
\hline$\geq 30$ & 2429 & 34.4 & 32.8 \\
\hline Missing & 89 & & \\
\hline \multicolumn{4}{|l|}{ Cardiovascular disease } \\
\hline No & 6865 & 96.1 & 96.7 \\
\hline Yes & 281 & 3.9 & 3.3 \\
\hline \multirow[t]{2}{*}{ Missing } & 8 & & \\
\hline & Unweighted Mean & Unweighted SE & Weighted Mean (SE) \\
\hline Age & 42.2 & 13.0 & $41.8(0.3)$ \\
\hline Ratio of family income to poverty (PIR) & 2.62 & 1.70 & $3.10(0.1)$ \\
\hline My Nutrition Index & 50.8 & 18.6 & $51.3(0.4)$ \\
\hline Healthy Eating Index & 53.5 & 16.9 & $53.5(0.3)$ \\
\hline
\end{tabular}




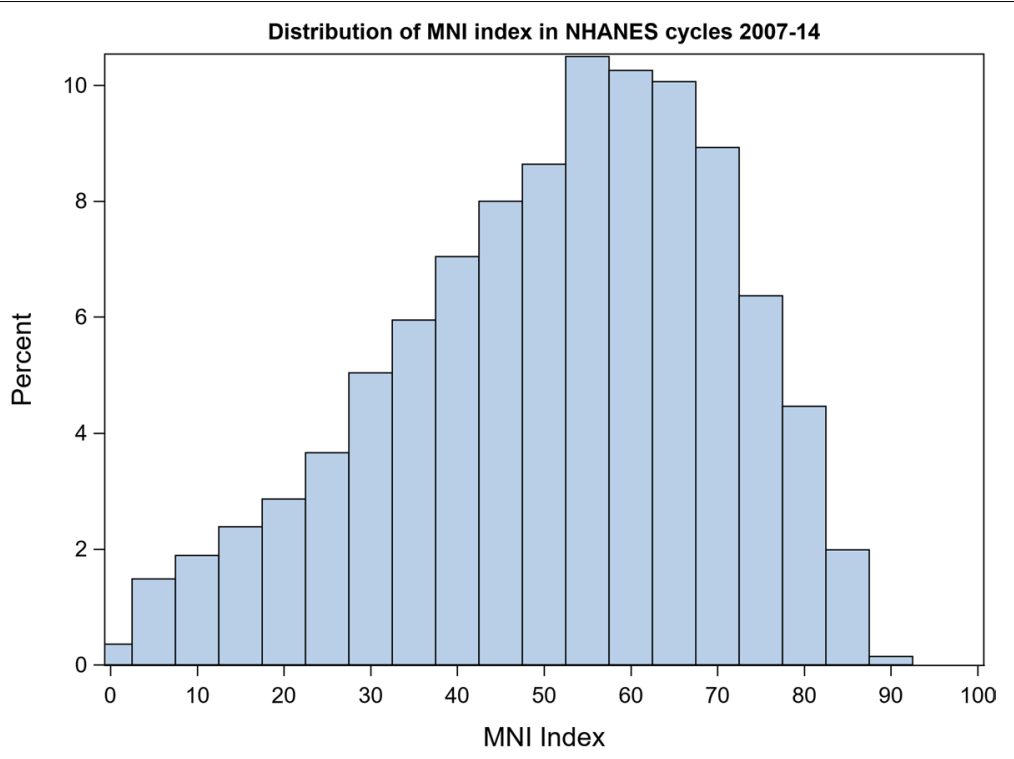

Fig. 1 MNI distributions among participants aged 18-65 from NHANES cycle 2007-2014

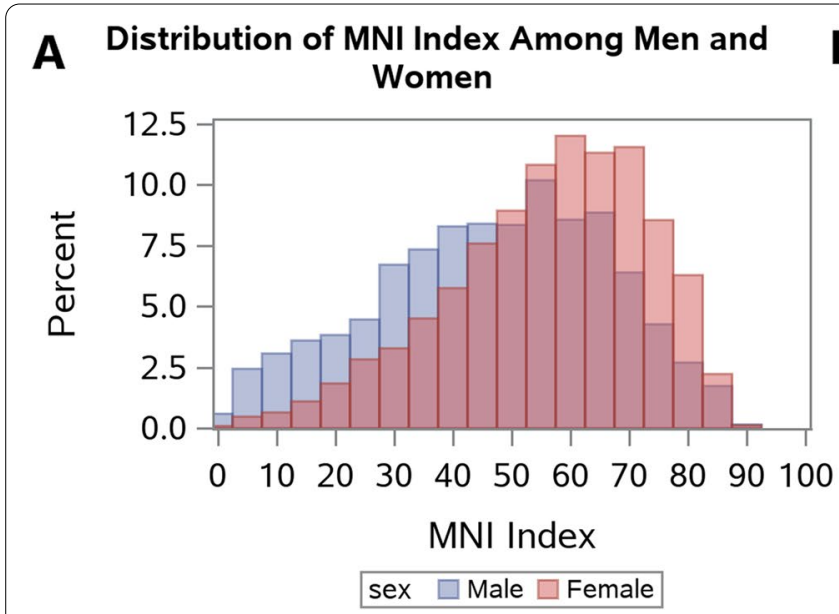

\section{B Distribution of MNI Index Among Smokers and} Nonsmokers

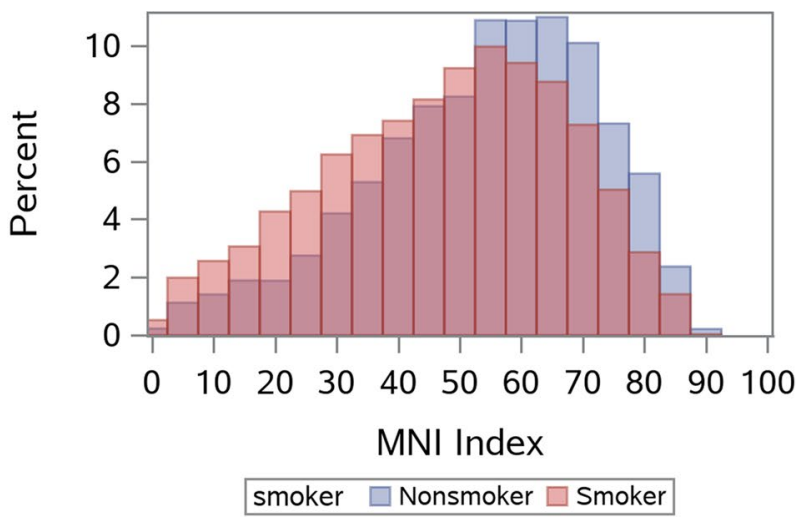

Fig. 2 A comparison of MNI distributions among (a) men and women and (b) smokers and nonsmokers from NHANES 2007-2014

variable. This suggests that MNI may capture a broader spectrum of eating behaviors. Still, MNI and HEI scores were similarly associated with the health outcomes examined herein which provides additional support for the construct and criterion validity of MNI.

Despite its similarities with HEI in terms of distribution and associations with health outcomes, MNI is an innovative research tool. It is unique in that its calculations can account for any personal characteristic, lifestyle factor or health condition for which there are specific Dietary Reference Intake guidelines. For example, the Dietary Reference Intakes recommend that smokers should have higher vitamin $C$ intake [71], given that smoking can affect vitamin $\mathrm{C}$ metabolism [72-75]. Therefore, if two people with otherwise equal characteristics eat the exact same foods in a given day and have average Vitamin C intakes, yet one is a smoker, the nonsmoker would have a higher MNI score. To our knowledge, HEI does not take in to account these additional lifestyle behaviors. Additionally, lactating women have higher selenium and potassium guidelines [76] and this is reflected in their MNI scores. Pick et al. examined HEI in pregnant women and concluded that it failed to discern micronutrient deficiencies unique to pregnancy and that a new HEI, specific for nutrient needs during pregnant should be developed [77]. Not only can the MNI index 


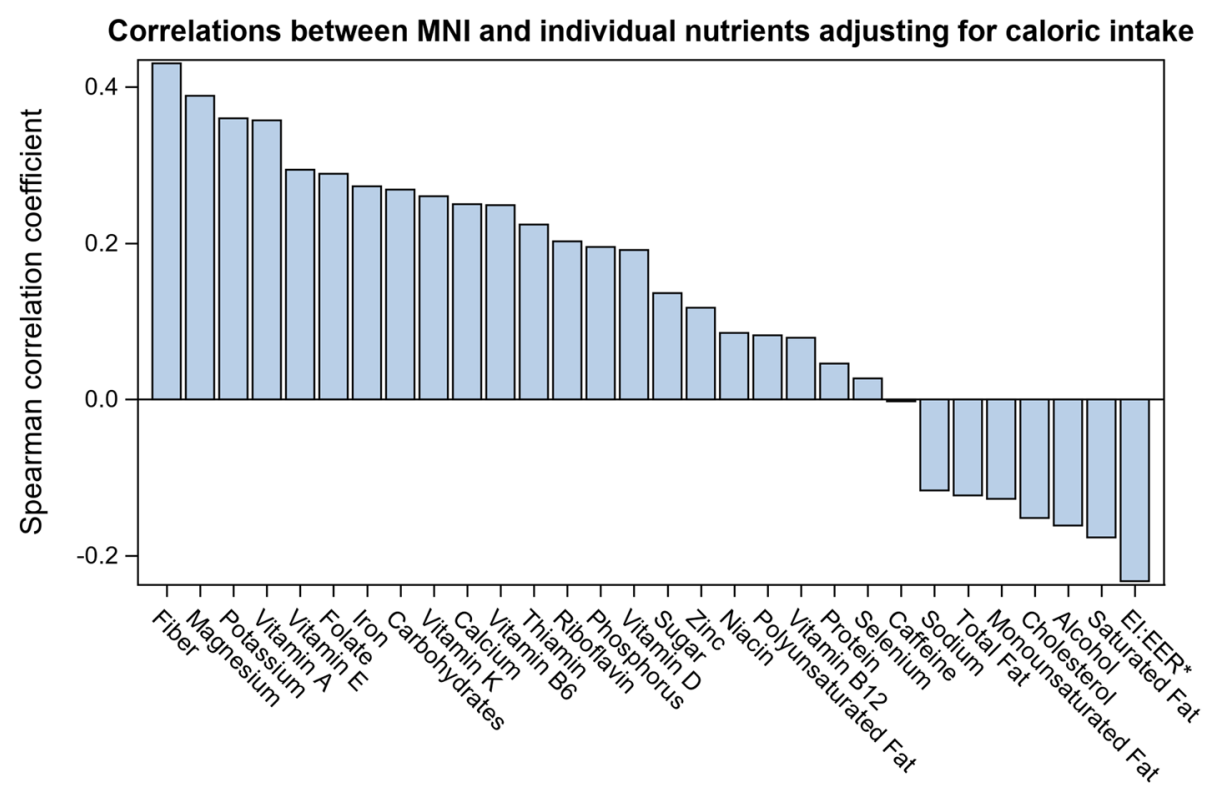

Nutrient

All nutrients are divided by energy intake

${ }^{*} \mathrm{El}: \mathrm{EER}=$ energyintake/estimated energy requirement.

Fig. 3 Pearson correlations of the MNI index with each individual nutrient, adjusted for caloric intake

Table 2 Associations of a 10-point change in MNI score with health outcomes

\begin{tabular}{llll}
\hline & OR & 95\% Cl & p-value \\
\hline Obesity $(n=7112)$ & 0.92 & $0.87,0.99$ & $0.016^{*}$ \\
Self-reported health $(n=7149)$ & 1.24 & $1.13,1.37$ & $<0.001^{* * *}$ \\
Depression $(n=6105)$ & 0.76 & $0.65,0.90$ & $<0.001^{* * *}$ \\
CVD $(n=5860)$ & 0.69 & $0.52,0.92$ & $0.012^{*}$ \\
\hline
\end{tabular}

CVD Cardiovascular diseases; Participants were adults aged 18-65 in NHANES 2007-2014; analyses were adjusted for age, sex, race, education, and healthcare access; sampling weights were applied for regression analyses; Weighted Ns: obesity, $N=87,314,021$; self-reported health, $N=87,836,410$; depression, $N=73,671,431 ; C V D, N=72,605,406$

${ }^{*} p<0.05 ;{ }^{* *} p<0.01 ;{ }^{* * *} p<0.001$

be adjusted by population level recommendations, but it can also be personalized such that an individual can work with their health care provider or nutritionist to accommodate whatever health or lifestyle deviations may be needed to determine the optimal level for that person. For example, if results of a blood test indicate that a patient has low iron, the health care provider could adjust the index so that the highest MNI score is attained only at a higher level of dietary iron, compared to someone with normal iron levels. Furthermore, in accordance with established nutritional guidelines, MNI uniquely considers excess consumption of certain nutrients aversive. For example, excess consumption of iron can increase oxidative stress and contribute to neurotoxicity [78-80]. Therefore, excess consumption and under consumption of this nutrient would lower an individual's MNI score.

Another benefit of MNI over HEI is the ability to incorporate supplemental nutrients in addition to dietary nutrients. MNI has the capability to account for different recommendations of a nutrient, depending on its source - food or supplements. Supplemental nutrients are also important for a healthy diet. For example, iodine is an important micronutrient, especially during pregnancy. Iodine in dietary sources can be scarce so fortification and supplementation are often used. In the current study, we chose to focus on the nutrient data from dietary, beverage, and water sources only. For this reason, iodine was not included in our index due to the lack of data on dietary iodine. However, NHANES provides data on iodine from supplements and thus can be incorporated in future iterations of the index.

\section{Limitations}

Nutritional adequacy measurements with MNI are subject to several limitations. As with other approaches, MNI measurements that rely on self-reported food intake measures, such as food frequency questionnaires or dietary recalls for example, may be subject to recall biases and/or social desirability. The nutrient values used in this analysis were based on a short-term dietary assessment metric and thus may not be reflective of long-term 


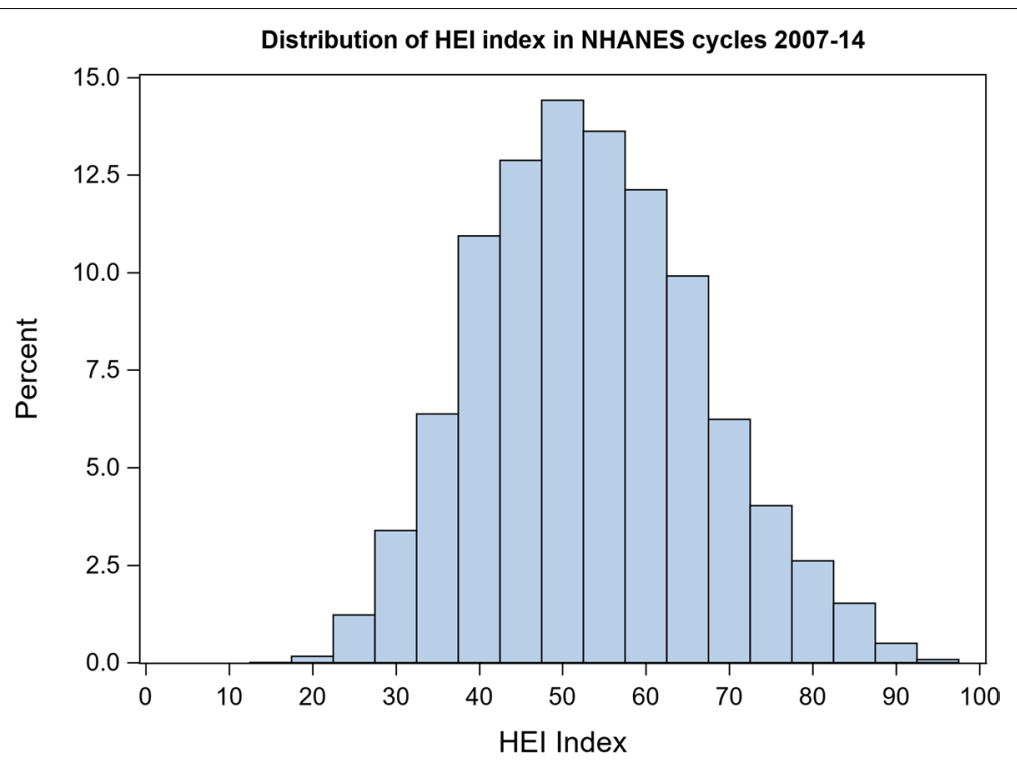

Fig. 4 HEl distributions among participants aged 18-64 from NHANES cycle 2007-2014

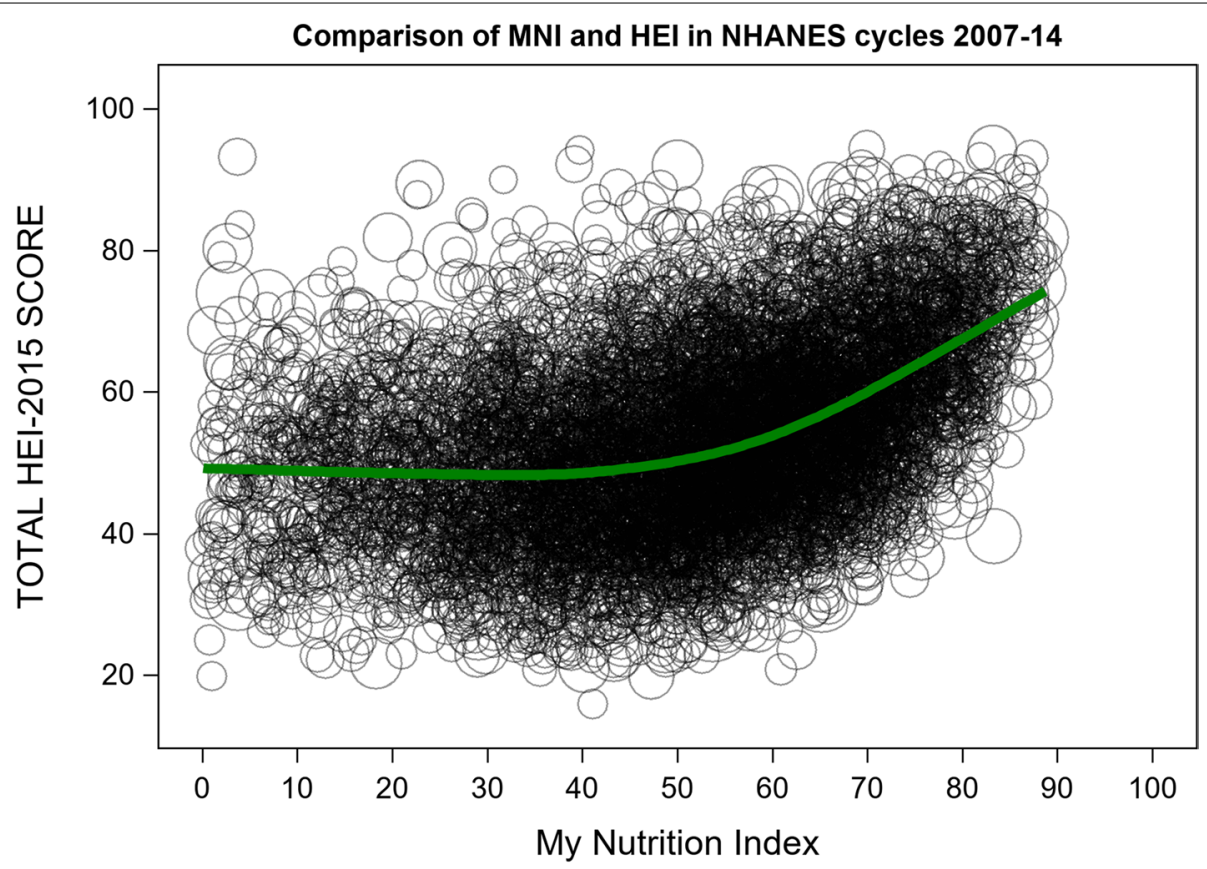

size of bubble represents two-day dietary weight

Fig. 5 Comparison of My Nutrition Index and the Healthy Eating Index from NHANES cycle 2007-2014

eating behaviors. Additionally, like HEI scores, MNI scores assess food-based nutritional adequacy and thus do not account for supplement intake. Therefore, they may not capture true total daily nutrient intake. Nutrient intake misclassification may bias associations with health outcomes to the null; however, in our analyses we still found significant associations. Third, while MNI accounts for a breadth of nutrients and personal characteristics, it does not account for nutrients that do not have established values for Recommended Dietary Allowance (RDA) or values of Adequate Intake when insufficient evidence is available to establish an RDA. Over time, and 
Table 3 Associations between HEl scores and health outcomes

\begin{tabular}{llll}
\hline & OR & 95\%Cl & $\boldsymbol{p}$-values \\
\hline Obesity $(n=7112)$ & 0.74 & $0.69,0.80$ & $<0.001^{* * *}$ \\
Self-reported health $(n=7149)$ & 1.23 & $1.11,1.36$ & $<0.001^{* * *}$ \\
Depression $(n=6105)$ & 0.71 & $0.61,0.82$ & $<0.001^{* * *}$ \\
CVD $(n=5860)$ & 0.52 & $0.37,0.74$ & $<0.001^{* * *}$
\end{tabular}

CVD Cardiovascular diseases; Participants were adults aged 18-65 in NHANES 2007-2014; analyses were adjusted for age, sex, race, education, and healthcare access; sampling weights were applied for regression analyses; Weighted Ns: obesity, $N=87,314,021$; self-reported health, $N=87,836,410$; depression, $N=73,671,431 ; C V D, N=72,605,406$

${ }^{*} p<0.05 ;{ }^{* *} p<0.01 ;{ }^{* * *} p<0.001$

with more research, additional nutrients with established guidelines can be incorporated into the MNI calculations. (e.g., copper and iodine). Lastly, in examining associations between MNI and health outcomes, we utilized cross-sectional data which is limited for determining directionality of associations found. In future studies, we plan to prospectively examine whether the individualized approach to nutritional adequacy assessment of MNI can predict relationships with health outcomes over time.

\section{Conclusion}

MNI is a novel research tool that measures nutritional value of an individual's daily diet according to his or her personal characteristics, lifestyle factors and health status. MNI provides a dietary nutrition assessment that validly captures associations between overall dietary nutritional value and health outcomes in populationbased studies.

\section{Abbreviations}

MNI: My Nutrition Index; NHANES: National Health and Nutrition Examination Survey; HEl: Healthy Eating Index; BMI: Body mass index; RDA: Recommended Dietary Allowance.

\section{Supplementary Information}

The online version contains supplementary material available at https://doi. org/10.1186/s40795-022-00497-9.

\section{Additional file 1.}

\section{Acknowledgements}

We would like to thank the Centers for Disease Control and Prevention (CDC) for conducting NHANES as well as the participants of the 2007-2014 NHANES cycles, without whom this research would not have been possible.

\section{Authors' contributions}

SAB conceptualized project and data analysis plan, performed data analysis, and wrote original draft of paper. AJM conceptualized project and data analysis plan and was a major contributor of writing the manuscript. CG conceptualized project and data analysis plan, calculated my nutrition index for each participant, and edited manuscript. The authors read and approved the final manuscript.

\section{Funding}

This work was supported by funding from the Mount Sinai Children's Center Foundation and NIH/NIEHS: P30ES023515 and R01ES028811-01. There was no additional external funding received for this study.

\section{Availability of data and materials}

The datasets generated and/or analyzed during the current study are available on the Center for Disease Control and Preventions website at https://www. cdc.gov/nchs/nhanes/index.htm.

\section{Declarations}

\section{Ethics approval and consent to participate}

The necessary IRB approval for NHANES had been obtained by the National Center for Health Statistics (NCHS) [23]. All methods were carried out in accordance with relevant guidelines and regulations. Adult participants provided written informed consent. Parental/ guardian written informed consent was obtained for children. Children/adolescents $\geq 12 y$ provided additional written consent. All NHANES data, used in the current study, are readily and publicly available on the NCHS and USDA websites [14]. Per Mount Sinai School of Medicine policies, public data do not involve "human subjects" and their use requires neither IRB review nor an exempt determination. Such data may be used without any involvement of the Human Subjects Division or the Mount Sinai Institutional Review Board.

\section{Consent for publication}

Not applicable.

\section{Competing interests}

The authors declare that they have no competing interests.

\section{Author details}

${ }^{1}$ Department of Environmental Medicine and Public Health, Icahn School of Medicine at Mount Sinai, New York, USA. ${ }^{2}$ Keck School of Medicine of USC, 2001 N Soto St., Los Angeles, California, USA.

Received: 6 August 2021 Accepted: 28 December 2021

Published online: 21 February 2022

\section{References}

1. Imoberdorf R, Ruhlin M, Ballmer PE. Cancer and nutrition - a paradigma shift. Laryngorhinootologie. 2017;96(8):514-8. https://doi.org/10.1055/s0043-109174 Epub 2017/08/30. PubMed PMID: 28850991.

2. Houston M. The role of noninvasive cardiovascular testing, applied clinical nutrition and nutritional supplements in the prevention and treatment of coronary heart disease. Ther Adv Cardiovasc Dis. 2018;12(3):85-108. https://doi.org/10.1177/1753944717743920 Epub 2018/01/11. PubMed PMID: 29316855; PubMed Central PMCID: PMCPMC5933539.

3. Schwingshackl L, Hoffmann G, Lampousi AM, Knuppel S, lqbal K, Schwedhelm C, et al. Food groups and risk of type 2 diabetes mellitus: a systematic review and meta-analysis of prospective studies. Eur J Epidemiol. 2017;32(5):363-75. https://doi.org/10.1007/s10654-017-0246y Epub 2017/04/12. PubMed PMID: 28397016; PubMed Central PMCID: PMCPMC5506108.

4. Vorster HH. Nutrient adequacy. World Rev Nutr Diet. 2015;111:7-12. https://doi.org/10.1159/000362290 Epub 2014/11/25. PubMed PMID: 25418382.

5. Margetts BM, Nelson M. Measuring dietary exposure in nutritional epidemiological studies. Nutr Res Rev. 1995;8(1):165-78. https://doi.org/10. 1079/nrr19950011 Epub 1995/01/01. PubMed PMID: 19094284.

6. Bowman SA, Gerrior MLSA, Basiotis PP. The healthy eating index, 1994-96. Fam Econ Nutr Rev. 1998;11(3):2

7. Kennedy T, E, Ohls J, Carlson S, Fleming K. The healthy eating index: design and applications. J Am Diet Assoc. 1995;95(10):1103-8.

8. Variyam J, Blaylock J, Smallwood D. USDA's healthy eating indexand nutrition information. Washington, DC: Economic ResearchService, US Department of Agriculture; 1998. (Technical Bulletinno. 1866.) 
9. U.S. Department of Agriculture and U.S. Department of Health and Human Services. Nutrition and Your Health: Dietary Guidelines for Americans. Home and Garden Bulletin No 232, vol. 4; 1995.

10. Bach A, Serra-Majem L, Carrasco JL, Roman B, Ngo J, Bertomeu I, et al. The use of indexes evaluating the adherence to the Mediterranean diet in epidemiological studies: a review. Public Health Nutr. 2007;9(1a). https:// doi.org/10.1079/phn2005936.

11. Karanja NM, Obarzanek E, Lin P-H, McCullough ML, Phillips KM, Swain $J$ J, et al. Descriptive characteristics of the dietary patterns used in the dietary approaches to stop hypertension trial. J Am Diet Assoc. 1999;99(8):S19-27.

12. Mattei J, Bhupathiraju S, Tucker KL. Higher adherence to a diet score based on American Heart Association recommendations is associated with lower odds of allostatic load and metabolic syndrome in Puerto Rican adults. J Nutr. 2013;143(11):1753-9. https://doi.org/10.3945/jn.113. 180141 Epub 09/04. PubMed PMID: 24005611.

13. Hu FB. Dietary pattern analysis: a new direction in nutritional epidemiology. Current opinion in lipidology. 2002;13(1):3-9.

14. Gennings C, Wolk A, Hakansson N, Lindh C, Bornehag C-G. Contrasting prenatal nutrition and environmental exposures in association with birth weight and cognitive function in children at 7 years. BMJ nutrition, prevention \& health. 2020;3(2):162

15. U.S. Department of Health and Human Services and U.S. Department of Agriculture. 2015-2020 Dietary Guidelines for Americans. December 2015 [cited 2018 Sept 17]. 8:[Available from: http://health.gov/dietarygui delines/2015/guidelines/].

16. Del Valle HB, Yaktine AL, Taylor CL, Ross AC. Dietary reference intakes for calcium and vitamin D: National Academies Press; 2011.

17. National Research Council. Dietary reference intakes for calcium, phosphorus, magnesium, vitamin D, and fluoride. Washington (DC): National Academy Press; 1997.

18. Trumbo P, Yates AA, Schlicker S, Poos M. Dietary reference intakes: vitamin A, vitamin $K$, arsenic, boron, chromium, copper, iodine, iron, manganese, molybdenum, nickel, silicon, vanadium, and zinc. J Acad Nutr Diet. 2001;101(3):294.

19. Krinsky NI, Beecher G, Burk R, Chan A, Erdman JJ, Jacob R, et al. Dietary reference intakes for vitamin $C$, vitamin $E$, selenium, and carotenoids. Institute of Medicine; 2000.

20. NHANES. About the National Health and Nutrition and Examination Survey. Available from: http://www.cdc.gov/nchs/nhanes/about_nhanes.htm.

21. Ramirez-Silva I, Jimenez-Aguilar A, Valenzuela-Bravo D, Martinez-Tapia B, Rodriguez-Ramirez S, Gaona-Pineda EB, et al. Methodology for estimating dietary data from the semi-quantitative food frequency questionnaire of the Mexican National Health and Nutrition Survey 2012. Salud Publica Mex. 2016;58(6):629-38. https://doi.org/10.21149/spm.v58i6.7974 Epub 2017/02/23. PubMed PMID: 28225939.

22. van Strien T, Konttinen H, Homberg JR, Engels RC, Winkens LH. Emotional eating as a mediator between depression and weight gain. Appetite. 2016;Epub 2016/02/26(100):216-24. https://doi.org/10.1016/j.appet.2016. 02.034 PubMed PMID: 26911261.

23. Casiero D, Frishman WH. Cardiovascular complications of eating disorders. Cardiol Rev. 2006;14(5):227-31. https://doi.org/10.1097/01.crd.00002 16745.96062.7c Epub 2006/08/23. PubMed PMID: 16924163.

24. Institute of Medicine. Dietary reference intakes for thiamin, riboflavin, niacin, vitamin B6, folate, vitamin B12, pantothenic acid, biotin, and choline. Washington, DC: The National Academies Press; 1998. p. 592.

25. Institute of Medicine. Dietary reference intakes for energy, carbohydrate, Fiber, fat, fatty acids, cholesterol, protein, and amino acids. Washington, DC: The National Academies Press; 2005. p. 1358.

26. National Academies of Sciences $E$, and Medicine,. Dietary reference intakes (dris) and tolerable upper intake levels 2010. Available from: http://www.nationalacademies.org/hmd/ /media/Files/Activity\%20Files/ Nutrition/DRI-Tables/5Summary\%20TableTables\%2014.pdf?la=en.

27. US Department of Health Human Services. Dietary guidelines for Americans 2015-2020. Skyhorse Publishing Inc.; 2017.

28. US Food and Drug Administration. Spilling theBeans: How Much Caffeine is Too Much?; 2019. [Available from: https://www.fda.gov/consumers/ consumer-updates/spilling-beans-how-much-caffeine-too-much]

29. Mifflin MD, St Jeor ST, Hill LA, Scott BJ, Daugherty SA, Koh YO. A new predictive equation for resting energy expenditure in healthy individuals. Am J Clin Nutr. 1990;51(2):241-7.
30. Moshfegh AJ, Rhodes DG, Baer DJ, Murayi T, Clemens JC, Rumpler WV, et al. The US Department of Agriculture Automated Multiple-Pass Method reduces bias in the collection of energy intakes. Am J Clin Nutr. 2008;88(2):324-32.

31. FNDDS. Food and nutrient database for dietary studies. 2013. (Service UAR, ed) [Available from: https://http://www.ars.usda.gov/northeastarea/beltsville-md/beltsville-human-nutrition-research-center/foodsurveys-research-group/docs/fndds-download-databases/.]

32. Romieu I, Dossus L, Barquera S, Blottière HM, Franks PW, Gunter M, et al. Energy balance and obesity: what are the main drivers? Cancer Causes Control. 2017;28(3):247-58.

33. Nicklas TA, O'Neil CE, Fulgoni VL III. Diet quality is inversely related to cardiovascular risk factors in adults. J Nutr. 2012;142(12):2112-8.

34. Reedy J, Krebs-Smith SM, Miller PE, Liese AD, Kahle LL, Park Y, et al. Higher diet quality is associated with decreased risk of all-cause, cardiovascular disease, and cancer mortality among older adults. J Nutr. 2014;144(6):881-9.

35. Estruch R, Ros E, Salas-Salvadó J, Covas M-I, Corella D, Arós F, et al. Primary prevention of cardiovascular disease with a Mediterranean diet supplemented with extra-virgin olive oil or nuts. N Engl J Med. 2018;378(25):e34.

36. Lai JS, Hiles S, Bisquera A, Hure AJ, McEvoy M, Attia J. A systematic review and meta-analysis of dietary patterns and depression in communitydwelling adults. Am J Clin Nutr. 2014;99(1):181-97.

37. Ghimire S, Baral BK, Feng D, Sy FS, Rodriguez R. Is selenium intake associated with the presence of depressive symptoms among US adults? Findings from National Health and nutrition examination survey (NHANES) 2011-2014. Nutrition. 2019;62:169-76.

38. Zhang R, Sun J, LiY, Zhang D. Associations of $n-3, n-6$ fatty acids intakes and $n-6: n-3$ ratio with the risk of depressive symptoms: NHANES 2009-2016. Nutrients. 2020;12(1):240.

39. Goodwin DK, Knol LL, Eddy JM, Fitzhugh EC, Kendrick OW, Donahue RE. The relationship between self-rated health status and the overall quality of dietary intake of US adolescents. J Am Diet Assoc. 2006;106(9):1450-3.

40. Kroenke K, Spitzer RL, Williams JB. The PHQ-9: validity of a brief depression severity measure. Journal of general internal medicine. 2001;16(9):606-13.

41. Kroenke K, Spitzer RL, Williams JB, Lowe B. The patient health questionnaire somatic, anxiety, and depressive symptom scales: a systematic review. Gen Hosp Psychiatry. 2010;32(4):345-59. https://doi.org/10. 1016/j.genhosppsych.2010.03.006 Epub 2010/07/17. PubMed PMID: 20633738.

42. Spitzer RL, Kroenke K, Williams JB. Patient Health Questionnaire Primary CareStudy Group. Validation and utility of a self-report version of PRIMEMD: the PHQprimary care study. JAMA. 1999;282:1737-1744.

43. World Health Organization. Obesity: preventing and managing the global epidemic. 2000.

44. Nuttall FQ. Body mass index: obesity, BMl, and health: a critical review. Nutr Today. 2015;50(3):117.

45. Ford ES. Trends in predicted 10-year risk of coronary heart disease and cardiovascular disease among U.S. adults from 1999 to 2010. J Am Coll Cardiol. 2013;61 (22):2249-52. https://doi.org/10.1016/j.jacc.2013.03.023 Epub 2013/04/09. PubMed PMID: 23563124; PubMed Central PMCID: PMCPMC4571185.

46. Costantino S, Paneni F, Cosentino F. Ageing, metabolism and cardiovascular disease. J Physiol. 2016;594(8):2061-73. https://doi.org/10.1113/jp270 538 Epub 2015/09/24. PubMed PMID: 26391109; PubMed Central PMCID: PMCPMC4933114.

47. Jura M, Kozak LP. Obesity and related consequences to ageing. Age (Dordr). 2016;38(1):23. https://doi.org/10.1007/s11357-016-9884-3 Epub 2016/02/06. PubMed PMID: 26846415; PubMed Central PMCID: PMCPMC5005878.

48. Salk RH, Hyde JS, Abramson LY. Gender differences in depression in representative national samples: Meta-analyses of diagnoses and symptoms. Psychol Bull. 2017;143(8):783-822. https://doi.org/10.1037/bul0000102 Epub 2017/04/28. PubMed PMID: 28447828; PubMed Central PMCID: PMCPMC5532074.

49. Mohaddesi H, Saei Ghare Naz M, Najarzadeh M, Yeganehpour M, Khalkhali H. Correlation between Depression with Serum Levels of Vitamin D, Calcium and Magnesium in Women of Reproductive Age. J Caring Sci. 2019;8(2):117-9. https://doi.org/10.15171/jcs.2019.017 Epub 2019/06/30. PubMed PMID: 31249822; PubMed Central PMCID: PMCPMC6589482. 
50. Curry Owens T, Jackson FM. Examining life-course socioeconomic position, contextualized stress, and depression among well-educated AfricanAmerican pregnant women. Womens Health Issues. 2015;25(4):382-9. https://doi.org/10.1016/j.whi.2015.05.001 Epub 2015/07/06. PubMed PMID: 26143076.

51. Viinikainen J, Bryson A, Bockerman P, Elovainio M, Pitkanen N, PulkkiRaback L, et al. Does education protect against depression? Evidence from the young Finns study using Mendelian randomization. Prev Med. 2018;115:134-9. https://doi.org/10.1016/.ypmed.2018.08.026 Epub 2018/08/27. PubMed PMID: 30145350

52. Munt AE, Partridge SR, Allman-Farinelli M. The barriers and enablers of healthy eating among young adults: a missing piece of the obesity puzzle: A scoping review. Obes Rev. 2017;18(1):1-17. https://doi.org/10.1111/ obr.12472 Epub 2016/10/21. PubMed PMID: 27764897.

53. Ford DW, Hartman TJ, Still C, Wood C, Mitchell DC, Bailey R, et al. Diet quality and body mass index are associated with health care resource use in rural older adults. J Acad Nutr Diet. 2014;1 14(12):1932-8. https:// doi.org/10.1016/j.jand.2014.02.016 Epub 2014/04/22. PubMed PMID: 24746773; PubMed Central PMCID: PMCPMC4568998.

54. National Center for Health Statistics. Overview of NHANES Survey Design and Weights 2013 [cited 2018 November 21]. Available from: https:// www.cdc.gov/Nchs/tutorials/environmental/orientation/sample_design/ index.htm

55. McGee DL, Liao Y, Cao G, Cooper RSJAjoe. Self-reported health status and mortality in a multiethnic US cohort. Am J Epidemiol. 1999;149(1):41-6.

56. Guenther PM, Kirkpatrick SI, Reedy J, Krebs-Smith SM, Buckman DW, Dodd KW, et al. The Healthy Eating Index-2010 is a valid and reliable measure of diet quality according to the 2010 Dietary Guidelines for Americans. J Nutr. 2014;144(3):399-407. https://doi.org/10.3945/jn.113. 183079 Epub 2014/01/24. PubMed PMID: 24453128; PubMed Central PMCID: PMCPMC3927552

57. Milner JA. Functional foods and health promotion. J Nutr. 1999;129(7):1395S-7S. https://doi.org/10.1093/jn/129.7.1395S.

58. Ishihara J. Challenges in dietary exposure assessment in epidemiology: research trends. J Nutr Sci Vitaminol. 2015;61(Suppl):S33-5. https://doi. org/10.3177/jnsv.61.S33 Epub 2015/11/26. PubMed PMID: 26598878.

59. Rehm CD, Peñalvo JL, Afshin A, Mozaffarian D. Dietary intake among US adults, 1999-2012Diet trends among US adults, 1999-2012Diet trends among US adults, 1999-2012. JAMA. 2016;315(23):2542-53. https://doi. org/10.1001/jama.2016.7491.

60. Courtenay WH, McCreary DR, Merighi JR. Gender and ethnic differences in health beliefs and behaviors. J Health Psychol. 2002;7(3):219-31.

61. Sanchez-Villegas A, Martinez JA, De Irala J, Martinez-Gonzalez M, group Sr. Determinants of the adherence to an "a priori" defined Mediterranean dietary pattern. Eur J Nutr. 2002:41 (6):249-57.

62. Chiolero A, Wietlisbach V, Ruffieux C, Paccaud F, Cornuz J. Clustering of risk behaviors with cigarette consumption: a population-based survey. Prev Med. 2006;42(5):348-53.

63. Serdula MK, Byers T, Mokdad AH, Simoes E, Mendlein JM, Coates RJ. The association between fruit and vegetable intake and chronic disease risk factors. Epidemiology. 1996;7(2):161-5.

64. Thompson R, Margetts B, Wood D, Jackson A. Cigarette smoking and food and nutrient intakes in relation to coronary heart disease. Nutr Res Rev. 1992;5(1):131-52.

65. Agarwal S, Reider C, Brooks JR, Fulgoni VL 3rd. Comparison of prevalence of inadequate nutrient intake based on body weight status of adults in the United States: an analysis of NHANES 2001-2008. J Am Coll Nutr. 2015;34(2):126-34. https://doi.org/10.1080/07315724.2014.901196 Epub 2015/01/08. PubMed PMID: 25564766.

66. Park YH, Choi-Kwon S, Park KA, Suh M, Jung YS. Nutrient deficiencies and depression in older adults according to sex: A cross sectional study. Nurs Health Sci. 2017;19(1):88-94. https://doi.org/10.1111/nhs.12315 Epub 2016/11/20. PubMed PMID: 27860217.

67. Gougeon L, Payette H, Morais JA, Gaudreau P, Shatenstein B, Gray-Donald K. A prospective evaluation of the depression-nutrient intake reverse causality hypothesis in a cohort of community-dwelling older Canadians. Br J Nutr. 2017;117(7):1032-41. https://doi.org/10.1017/s00071145170007 82 Epub 2017/05/04. PubMed PMID: 28462727.

68. Adriouch S, Julia C, Kesse-Guyot E, Ducrot P, Peneau S, Mejean C, et al. Association between a dietary quality index based on the food standard agency nutrient profiling system and cardiovascular disease risk among
French adults. Int J Cardiol. 2017;234:22-7. https://doi.org/10.1016/j.ijcard. 2017.02.092 Epub 2017/03/05. PubMed PMID: 28258849.

69. Mozaffarian D. Dietary and Policy Priorities for Cardiovascular Disease, Diabetes, and Obesity: A Comprehensive Review. Circulation. 2016;133(2):187-225. https://doi.org/10.1161/circulationaha.115.018585 Epub 2016/01/10. PubMed PMID: 26746178; PubMed Central PMCID: PMCPMC4814348.

70. Micha R, Penalvo JL, Cudhea F, Imamura F, Rehm CD, Mozaffarian D. Association Between Dietary Factors and Mortality From Heart Disease, Stroke, and Type 2 Diabetes in the United States. JAMA. 2017;317(9):91224. https://doi.org/10.1001/jama.2017.0947 Epub 2017/03/08. PubMed PMID: 28267855; PubMed Central PMCID: PMCPMC5852674.

71. Institute of Medicine. Dietary reference intakes for vitamin $C$, vitamin $E$, selenium, and carotenoids. National Academy Press; 2000.

72. Kevany J, Jessop W, Goldsmith A. The effect of smoking on ascorbic acid and serum cholesterol in adult males. Ir J Med Sci. 1975;144(1):474.

73. Hornig D, Glatthaar B. Vitamin C and smoking: increased requirement of smokers. Int J Vitam Nutr Res Suppl. 1985;27:139-55.

74. Schectman G. Estimating ascorbic acid requirements for cigarette smokers. Ann N Y Acad Sci. 1993;686(1):335-45.

75. Schectman G, Byrd JC, Gruchow HW. The influence of smoking on vitamin C status in adults. Am J Public Health. 1989;79(2):158-62.

76. Khayat S, Fanaei $\mathrm{H}$, Ghanbarzehi A. Minerals in pregnancy and lactation: A review article. J Clin Diagn Res. 2017;11 (9):QE01-QE5. https://doi.org/ 10.7860/JCDR/2017/28485.10626 Epub 2017/09/01. PubMed PMID: 29207789.

77. Pick ME, Edwards M, Moreau D, Ryan EA. Assessment of diet quality in pregnant women using the healthy eating index. J Am Diet Assoc. 2005;105(2):240-6.

78. Bremner I. Manifestations of copper excess. Am J Clin Nutr. 1998:67(5):1069S-73S. https://doi.org/10.1093/ajcn/67.5.1069S

79. Stankiewicz JM, Brass SD. Role of iron in neurotoxicity: a cause for concern in the elderly? Curr Opin Clin Nutr Metab Care. 2009;12(1):22-9. https://doi.org/10.1097/MCO.0b013e32831 ba07c Epub 2008/12/06. PubMed PMID: 19057183

80. Bulcke F, Dringen R, Scheiber IF. Neurotoxicity of copper. Adv Neurobiol. 2017;18:313-43. https://doi.org/10.1007/978-3-319-60189-2_16 Epub 2017/09/11. PubMed PMID: 28889275

\section{Publisher's Note}

Springer Nature remains neutral with regard to jurisdictional claims in published maps and institutional affiliations.

Ready to submit your research? Choose BMC and benefit from

- fast, convenient online submission

- thorough peer review by experienced researchers in your field

- rapid publication on acceptance

- support for research data, including large and complex data types

- gold Open Access which fosters wider collaboration and increased citations

- maximum visibility for your research: over 100M website views per year

At BMC, research is always in progress.

Learn more biomedcentral.com/submissions 